\title{
O exercício radiofônico como prática da palavra, da vocalidade e da escuta
}

The radio exercise as a practice of word, voicing and listening

Mirna Spritzer ${ }^{1}$ 


\section{Resumo}

O artigo é uma reflexão sobre o exercício da radiofonia como possibilidade de prática para atores tendo em vista a linguagem radiofônica e sua repercussão sobre o exercício teatral, apresentando questões ligadas à vocalidade, à escuta e à relação com a palavra.

Palavras-chave: Exercício radiofônico; vocalidade, palavra.

\section{Abstract}

The article is a reflection about the exercise of radio as a possible practice for actors owing to radio language and its impact on the theatrical exercise, presenting issues at voicing, listening and relationship with the word.

Keywords: Radio exercise; voicing; word.

ISSN: 1414.5731

\footnotetext{
1 Universidade Federal do Rio Grande do Sul (UFRGS). Profa Dra. do Programa de Pós-Graduação em Artes Cênicas. Porto Alegre (RS). mirna.spritzer@gmail.com
} 
Nós ouvimos dentro das palavras as coisas em suspenso, o mundo em suspenso nos nossos lábios, o instante falado, toda a matéria, todo o universo suspensos no instante da fala (Novarina, 2003, p. 20).

O exercício radiofônico fez de mim uma apaixonada pela voz. Menos da perspectiva de sua produção e mecanismos de fonação, e mais do ponto de vista de seu alcance, de sua presença no espaço. Formas de encontro, confronto e afeto. A ação de afetar o outro. O efeito da voz.

Encontrei nas práticas radiofônicas, possibilidades de oportunizar aos atores em formação a experiência de um sistema de trabalho baseado em reconhecer suas vocalidades e trabalhá-las usando a gravação, o microfone e a arte sonora como meio ou como um fim.

Cada vez mais a cena contemporânea apropria-se de recursos inúmeros seja da visualidade, seja da sonoridade. Assim, o exercício radiofônico oferece espaço para a experimentação sonora e vocal que pode repercutir nos trabalhos acústicos ou cênicos.

Paul Zumthor (1993, p. 21), mostrou-me o conceito que melhor capta minha abordagem do trabalho, vocalidade. Diz ele que vocalidade traz em si uma historicidade da voz e a trajetória do seu uso. A voz traz significados e palavras e, para além das palavras, incorpora sons. Na experiência radiofônica, é a forma de situar a ação, de colocar na voz o texto, a intenção e o repertório do ator. Tornar voz tudo o que é tempo, corpo e espaço.

O que me move é a sensação do ator ao microfone, o prazer de colocar na voz todas as possibilidades do corpo, a emoção de sussurrar ao ouvinte. $O$ rádio, para um ator, é um veículo extremamente fascinante e um espaço muito propício para exercer aquilo que nós atores fazemos, que é também sedução. Do palco, do corpo inteiro, da forma, do movimento e da voz. Acoplada aos efeitos, aos silêncios, ou sozinha, a voz é um poderoso mecanismo de sedução.

Para Analice Pillar (2003, p.13), "a sedução envolve tanto o ato de seduzir como o de ser seduzido, atraído, encantado, fascinado por alguém ou por algum objeto, por olhares e imagens que nos convidam a ler o mundo e a nos lermos de várias formas". Penso que a voz encanta, fascina e convida a ouvir o mundo.

A perspectiva da gravação em estúdio é de se estar falando muito diretamente a este outro que é o ouvinte, que é um e que são milhares. Esse fenômeno, essa característica primordial do rádio, é inebriante. Essa possibilidade de falar a cada um com a sua particularidade e ao mesmo tempo a todos que estão ouvindo rádio. E na certeza que estes muitos não ouvem a mesma coisa, não ouvem a mesma voz, não vêem o mesmo corpo e se sentem provocados nas suas memórias e nas suas imagens, de maneiras totalmente diversas.

A esse respeito, Klippert diz que:

Sendo que o seu efeito peculiar reside em que ele transmite simultaneamente para milhares e para cada indivíduo que recebe por si. $O$ rádio acopla uma tarefa individual a uma tarefa coletiva, fala ao sentido interior de cada um e procura o que há de humanamente 
comum em centenas de milhares de pessoas (1980, p.114).

Ao mesmo tempo, a vivência dessa experiência radiofônica me fez encontrar na literatura, ou melhor, no dizer a literatura trabalhando com leituras dramáticas e dramatizadas de textos de todos os gêneros, uma nova relação com a palavra. Atuar para ser ouvida, o foco na sonoridade, me levou também a procurar a palavra com outro olhar. E outro ouvir.

A experiência da vocalidade é uma vivência corporal e sensível para aquele que diz e para aquele que ouve. Conversar, contar histórias ou ler em voz alta para os outros, constituem um dizer que, para Bajard (1994), é a manifestação oral das palavras escritas ou não, mesmo mantendo as fronteiras do contar, ler em voz alta ou a fala teatral, por exemplo. Dizer inclui o gesto, a melodia das palavras, o olhar envolvente. Há um dizer no corpo. Um corpo palavra, portanto um corpo também no ouvir.

Na medida em que envolve semântica e imaginário, a palavra se desloca no espaço. Ainda uma vez mais, Zumthor:

[...] ela, a palavra, não é uma simples executora da língua, mas carrega sua verdade própria. A voz poética emerge, portanto, do fluxo mais ou menos indiferenciado dos ruídos e dos discursos. Ela faz o acontecimento. (...) No momento em que o diz, a voz transmuta o simbólico produzido pela linguagem, ela tende a despojá-lo do que ele comporta de arbitrário; ela o motiva com a presença deste corpo de onde emana. À extensão prosódica, à temporalidade da linguagem, a voz impõe assim sua espessura e a verticalidade de seu espaço (2005, p. 145).

A escuta ocupa o espaço. Embora o som atue no tempo ele se apropria do espaço na medida em que o momento da escuta é um momento de familiaridade, um momento que, para Barthes (1990), é a referência da casa, do território, é o que demarca os espaços em que existimos, em que convivemos com as pessoas. Para Humberto Maturana (2000, p.97), “a linguagem é uma maneira de vivermos juntos".

Ler em voz alta, falar ao microfone ou contar histórias, são momentos em que a voz adquire o estatuto de um corpo que ocupa o espaço e se apropria do tempo. Ao ouvinte cabe a oportunidade de entregar ao outro a tarefa de conduzi-lo pela viagem da escuta. Todas elas experiências que propiciam a imaginação, tanto para quem fala como para quem escuta.

A experiência da ficção radiofônica marca o espaço do rádio expressivo como um lugar para compartilhar a palavra que está entre o que fala e o que ouve e que é uma ponte para imaginação. Aqui, a voz é a senhora da ação, ou seja, a voz não é um elemento do todo, como no teatro, mas sim a protagonista.

A performance da palavra supõe sua existência como onda sonora, pressente sua trajetória pelo espaço até tocar o corpo que escuta. Assim prevista, esta palavra destrava a voz. Com o foco no dizer, o texto desprende-se da questão de significar ou soar e alcança o patamar da comunicação através da experiência, do acontecimento. Como comenta Benjamin (1994, p. 198) sobre a arte da narração, "A experiência que passa de pessoa a pessoa é a fonte a que recorreram todos os narradores". Parece possível associar narrador, ator e con- 
tador numa mesma esfera de apropriação da palavra incorporada, encarnada.

Nesse trabalho, é possível identificar nos alunos-atores de que forma os exercícios valorizam a sua relação com o dizer e como isso provoca sua imaginação criadora de diferentes formas. Percebemos de forma clara seu reencontro com a palavra e o fascínio pelo meio expressivo que o rádio é. Como refere Haye (2003, p. 11), "por sua própria essência, no rádio se faz imaginação com a voz, cenografia com a música, sonoridade com os efeitos e insinuações com o silêncio vibrante". ${ }^{2}$

Assim, a peça radiofônica tem se mostrado uma experiência pedagógica coletiva e criativa, que abre a atores e ouvintes a possibilidade da imaginação criadora e reinvenção da memória, conectando-se ao imaginário coletivo e à imaginação de cada um. Uma pedagogia da imaginação, construção de saberes que passam pela sensibilidade, pelas sensações, pelo corpo.

João Francisco Duarte Júnior ressalta que

buscar o universal no particular, e vice-versa, parece constituir, pois o grande desafio da educação contemporânea, tarefa para a qual esta não pode lançar mão apenas dos procedimentos estreitos e parciais permitidos pelo conhecimento lógico-conceitual, mas também ampliar sua área de atuação para os domínios corporais e sensíveis que nos são dados com a existência (2001, p. 172).

A experiência radiofônica traz aos atores a sensibilização da voz que, ao assumir-se como vocalidade, torna-se um exercício sensível aos ouvintes que reaprendem a imaginar através da provocação da escuta. Uma experiência como pedagogia na medida em que dá lugar a novas relações com a palavra, diferentes concepções de conhecimento e porque inclui falantes e ouvintes como sujeitos e objetos deste conhecimento.

Há um saber da experiência que não está fora de nós, mas que só tem sentido, como lembra Larrosa (1996, p.24), "no modo como configura uma personalidade, um caráter, uma sensibilidade ou, definitivamente, uma forma humana singular que é por um lado ética (um modo de conduzir-se) e por outro estética (um estilo)". ${ }^{3}$

No caso do ator, seu saber, sua educação, é a educação do sensível. Sua pedagogia é perceber o mundo e significá-lo em seu corpo. Corpo entendido como seu ser inteiro, sua subjetividade encarnada.

No já longo tempo dedicado aos estudos e práticas da vocalidade, repercutida pela experiência radiofônica, percebo que há uma entrega corporal nessa atividade que denuncia o acontecimento da voz. A arte da voz é corporal, é inteira e, portanto educá-la não pode ser apenas compreendê-la como acessório, como um aparelho de som. A pedagogia da voz implica em espaço de criação artístico-estética.

Na situação radiofônica a voz é a ação e, portanto, necessita de tempo e espaço para realizar-se como arte, o que inclui criação e instrumento. No rádio

\footnotetext{
${ }^{2}$ Tradução nossa.

3 Tradução nossa.
} 
a vocalidade compõe com sons, silêncios e música, o espetáculo sonoro. Compreendemos organicamente que a ação é a essência do teatro e também do rádio. Se no teatro ela gera o movimento dos conflitos, personagens e situações, no rádio ela determina a existência ou não dos personagens e acontecimentos, através das vozes e sons. É o câmbio de ritmo, de situação e de som que motiva a ação radiofônica. E é o que marca a presença de alguém na cena.

No decorrer do trabalho fomos criando um sistema que apropria os exercícios e questões da preparação do ator e seu processo de criação, para a especificidade da linguagem radiofônica, uma linguagem artística. Nessas circunstâncias, não importa a visibilidade das ações, do engajamento corporal, dos gestos e olhares, mas sim o efeito sonoro que eles acarretam. $O$ impulso emocional que origina a voz é importante na medida em que resulta em efeito sobre a relação ator ouvinte.

Iniciando sempre por um estudo de texto, o "trabalho de mesa" e pelas primeiras impressões destas palavras, buscamos encontrar a tradução radiofônica das questões que perpassam o trabalho do ator, como contracenação, personagem, emoção, mobilização do corpo para o exercício da atuação, a escuta, entre outras.

Baseado fundamentalmente nas ações de gravar e ouvir as leituras, os exercícios e os ensaios, esse sistema favorece o efeito da voz. Efeito aqui considerado não como truque, mas sim como estabelecimento da relação com o outro, nesse caso, o ouvinte. E também o parceiro de cena radiofônica. Efeito como o confrontar o outro com suas emoções, pensamentos e lembranças. Ato de sedução, trazer o outro para perto do rádio para ouvir e viver.

As gravações e audições acompanham todas as etapas. Vão demarcando de que forma o estudo começa a se revelar nas vozes, nas ações sonoras, no andamento da peça. Vão acostumando os atores com o meio. Vão se familiarizando com o microfone, com o ouvir-se, com deixar de lado a comparação com outros meios, em especial teatro, cinema e televisão, onde são vistos. Levam ao reconhecimento do veículo radiofônico como uma linguagem em si mesma, com características a serem apropriadas pelos atores. Uma vez que a gravação e audição são elementos próprios da linguagem, ao exercitá-las recriamos a linguagem e nos apropriamos dela. Ao contrário do teatro filmado, em que o que vemos não é nem teatro e nem cinema ou vídeo, na gravação o que ouvimos já é a linguagem radiofônica.

Do mesmo modo, essa forma essencialmente sonora repercute intensamente sobre o trabalho feito para teatro, uma vez que permite ao ator um investimento mais profundo na ação vocal. Permitir que a ação da voz sobre o texto tenha influência sobre a criação do personagem cênico. Um caminho de duas mãos, teatro e radiofonia, radiofonia e teatro. Ou ainda, a criação de improvisações sonoras construindo dramaturgia a partir de vocalidade e sonoridade. Cenários sendo desenhados a partir de paisagens sonoras. Tempos e pausas, silêncio e ação sonora transformando-se em diferentes durações cênicas. A percepção da relevância do uso de improvisações sonoras, ou a versão radiofônica das improvisações que ajudam a construir a verdade do 
personagem, é também bastante surpreendente e abre caminhos muito sedutores, pois possibilita imaginar, inclusive, a criação de peças radiofônicas a partir de improvisações.

A escuta no exercício radiofônico torna-se também corpo, uma vez que é o contraponto da voz. Temos sempre presente a concepção de uma escuta criativa e ativa, seja na parceria da contracenação, seja na interlocução com o ouvinte. Contracenar mostra-se uma ação de escuta sensível com todos os sentidos. E mais uma vez nos faz transportar essa ideia para o teatro, mostrando que a fala mecânica implica em escuta inerte e numa cena morta. No rádio a fala sem vida, sem organicidade, faz sucumbir a atmosfera.

O uso dos fones de ouvido é um auxiliar potente na contracenação. Ele dá o retorno imediato ao ator do seu dizer e potencializa o diálogo com o companheiro de cena. Os atores atuam com todo o foco na escuta de si e do outro. É perceber na prática a vivência de ser um e outro ao mesmo tempo, ator e ouvinte, podendo assim tomar as rédeas de sua atuação no instante mesmo da sua realização.

Temos um repertório de escuta que nos faz criar sons, vozes e ambientes ao mesmo tempo que nos faz reconhecer espaços e timbres. É desse repertório que nasce a composição vocal do ator e é o que sustenta a imaginação do ouvinte.

Também o trabalho realizado com foco no tempo e espaço mostra-nos que o parentesco com o teatro pode ser gratificante, se mantida a concentração em sua consequência sonora sobre a obra. A experimentação de espaços variados para repercutir as sonoridades da voz e das palavras traz a dimensão prática da ideia de duração em relação ao tempo e aos silêncios e pausas. Isso nos obriga, muitas vezes, a sair da lógica do significado liberando a musicalidade, a imaginação, a textura.

As relações que estabelecemos entre tempo, espaço, duração e intenção são conquistas inestimáveis para um processo de trabalho onde o saber é construído na prática. Mesmo que transposto para a composição de personagem de um texto dramático, ou para um texto literário onde o ator é o narrador, essas relações constituem o conhecimento que embasa tanto a técnica como a intuição. Implica na maneira de dizer e em como relacionar a extensão da fala com o tempo da respiração. O efeito que a fala produz está influenciado por esse tempo. No trabalho com o teatro, a tendência é que a fala seja uma consequência de como age o personagem. Talvez aqui possamos criar um caminho em que a intensidade da fala provoque a ação.

Trabalhando com os elementos da radiofonização, chega-se a um raciocínio radiofônico, acústico, em que é possível atingir os objetivos sonoros sem pensar antes no teatro. Ainda que o teatro nos traga sempre a base sólida para criar, o universo radiofônico nos permite mergulhar na linguagem, liberando suas qualidades para que deixem agir a atuação desde a perspectiva da composição sonora.

Nesse universo, então, descobrimos o cenário sonoro, a necessidade de colocar a voz dentro de um ambiente sonoro que a valorize e torne clara sua 
existência. É um cenário que se move, que troca de espaços e redistribui os tempos de forma a manter o ouvinte atento e localizá-lo em relação a ficção. É o suporte da sua imaginação.

Imaginação que move também o ator, apoiando a criação de um subtexto a preencher as entrelinhas do texto. O subtexto radiofônico estrutura o personagem, dando uma linha consistente para sua trajetória que precisa existir sonoramente. Da mesma forma, texto e subtexto convivem na concordância ou no confronto sempre harmoniosamente. Ou seja, ainda que contraditórios, ambos surgem na voz-corpo esclarecendo o momento em que se encontra o personagem, conflitado ou não. Há que estar preparado para vocalizar às vezes, duas sensações opostas.

Assim, falar passa a ser a base do personagem e também a manifestação da sua existência radiofônica. Falar ou produzir som, uma vez que inúmeras experiências contemporâneas usam a voz sem as palavras. Da mesma forma, o som, o efeito sonoro, quando trabalhado no exercício de criação das cenas, é o propulsor da ação sonora e na audição realimenta o personagem e a cena. Mais uma vez as ações de gravar e ouvir suprem a experiência com novas sonoridades e revelam vocalidades.

O trabalho com a peça radiofônica é sustentado por uma concepção de texto. Na maior parte das vezes utilizamos textos teatrais ou contos. Ambas as formas literárias necessitam adaptação, tendo em vista suas possibilidades de ação sonora. Muitas vezes, o sistema de Stanislavski nos oportuniza a migração de várias de suas ideias sobre o ator, o dizer, a palavra e a imaginação, para o exercício da peça radiofônica. Como quando o autor (1989, p. 494) se pergunta "como conseguir que o som na conversação seja contínuo, sucessivo, fundindo entre si palavras e frases inteiras, penetrando-as como a linha de um rosário sem cortá-las em sílabas?".

Certamente o trabalho feito para o palco, baseado no texto dramático, deve resultar interessante para qualquer veículo, mesmo que num tom diferente. Personagem, tempo, espaço e até a marcação que traz a lógica das relações e da ação dramática fazem sentido em qualquer linguagem ficcional.

Durante toda a investigação, tenho sempre a clareza de que trabalhamos sobre a formação. Mesmo no trabalho desenvolvido com atores profissionais essa dimensão ficava evidente, pois o caráter de procura, de aventura sobre as descobertas que a linguagem nos impõe, deixa claro que construímos um conhecimento original. A todo o momento, procuramos avaliar de que forma toda esta construção inclui-se nos estudos sobre o ator contemporâneo e sobre a pedagogia do ator.

Persigo uma concepção de pedagogia que me parece a mais coerente para o exercício da atuação, que é a da prática. Uma pedagogia do ator precisa ter como base seu repertório, a valorização daquilo que ele traz como bagagem. Não um leque de truques, não uma memória cristalizada, mas um acervo em constante recriação, um repertório que se refaz a cada performance, a cada ensaio, a cada improvisação. A ação no presente que caracteriza o ator deve se refletir no presente da aula, da sessão de trabalho, da gravação. E, na 
consequente reflexão sobre o exercício, construindo assim o sentido do que foi feito.

O exercício radiofônico oferece ao ator a ampliação de seus recursos, de seu repertório e a criação de uma obra insólita na sua materialidade sonora e na sua vocalidade corporal. A chance de criar um texto voz sobre o mundo e sobre a experiência de estar nele escutando seus sons e silêncios. Escuta é aprendizado e imaginação. E compondo vozes que digam as palavras, os sussurros, as interjeições, os suspiros, os bocejos, as gargalhadas e as lágrimas.

\section{Referências}

BAJARD, Elie. Ler e dizer. São Paulo: Cortez, 1994.

BARTHES, Roland. Escuta. In: BARTHES, Roland. O óbvio e o Obtuso. Rio de Janeiro: Nova Fronteira, 1990.

BENJAMIN, Walter. Obras Escolhidas - Magia e Técnica, Arte e Política. Vol 1. São Paulo: Brasiliense, 1994.

DUARTE Jr., João Francisco. O sentido dos Sentidos. A educação do sensível. Curitiba: Criar, 2001.

HAYE, Ricardo. Outro siglo de radio. Noticias de um médio cautivante. Buenos Aires: La Crujía, 2003.

KLIPPERT, Werner. Elementos da linguagem radiofônica. In: SPERBER, George Bernard. Introdução à Peça Radiofônica. São Paulo: Editora Pedagógica e Universitária, 1980.

LAROSSA, Jorge. La Experiência de la Lectura. Estúdios sobre literatura e formación. Barcelona: Laertes, 1996.

MATURANA, Humberto. Transdisciplinaridade e Cognição. In: BASARAB, Nicolescu et al. Educação e Transdisciplinaridade. Brasília: Edições UNESCO, 2000.

NOVARINA, Valère. Diante da Palavra. Rio de Janeiro: 7 Letras, 2003.

PILLAR, Analice. Da sedução ao sentido da imagem: televisão e arte na educação infantil. In: POTRICH, Cilene Maria; QUEVEDO, Hercílio Fraga de. (Orgs.) Questões de Arte e Comunicação. Passo Fundo: Editoria UPF, 2003.

STANISLASKI, Constantin. Minha Vida na Arte. Rio de Janeiro: Civilização Brasileira, 1989. 
ZUMTHOR, Paul. Escritura e Nomadismo. São Paulo: Ateliê Editorial, 2005.

. A Letra e a Voz. São Paulo: Cia. da Letras, 1993.

Recebido em 22/05/2014 Aprovado em 03/07/2014 